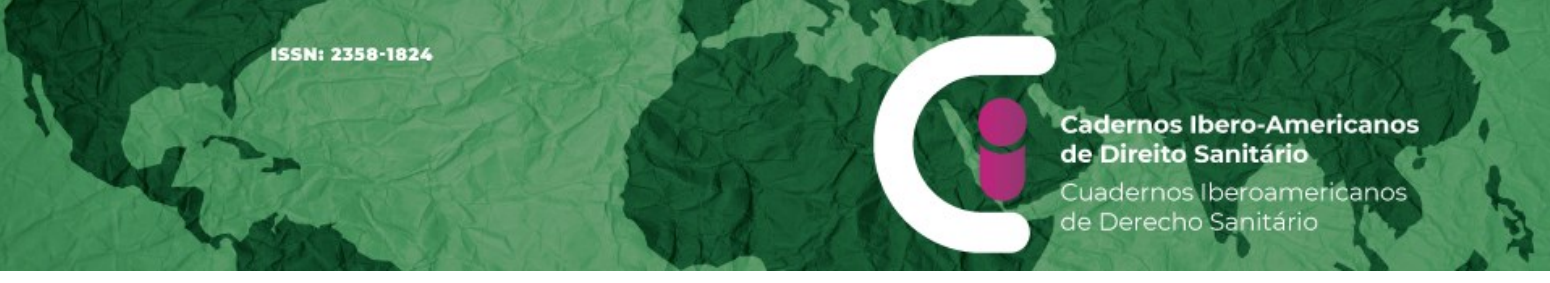

\title{
Critérios de triagem em pandemia: o factor idade
}

Pandemic triage criteria: the age factor

Criterios de triaje en la pandemia: el factor edad

Maria do Céu Patrão Neves ${ }^{1}$

\section{Resumo}

A triagem, ou priorização de doentes, iniciou-se como uma estratégia de sucesso para salvar o maior número possível de feridos. Ao longo da sua curta história, o sistema de triagem foi evoluindo, respondendo positivamente às necessidades clínicas dos doentes em diversas situações. Assumiu sempre uma inequívoca dimensão ética ao fundamentar-se no reconhecimento do igual valor de todas as vidas e ao estruturar-se sob a finalidade de salvar vidas. O escrutínio ético foca-se, pois, nos critérios de triagem: "primeiro a chegar, primeiro a cuidar" e "máxima severidade, máxima prioridade", "racionamento" e "racionalização" de recursos. A pandemia de SARS-CoV-2 desencadeou uma pressão ímpar nos recursos humanos e técnicos de saúde, o que conduziu a uma triagem de racionamento, baseada na idade cronológica como factor de exclusão, o que viola a dignidade humana e a justiça social. Simultaneamente apresenta-se como uma realidade equívoca, com uma argumentação débil, moldada por uma política de linguagem, e revelando uma lógica da acção abusiva dos direitos humanos, sendo, pois, eticamente inaceitável.

\section{Palavras-chave}

Triagem. Idade. Racionamento. Racionalização. Ética.

\section{Abstract}

Triage, or patients' prioritizing, started as a successful strategy to save as many wounded as possible. Throughout its short history, the triage system has evolved, responding positively to the clinical needs of patients in different situations. It has always taken on an unequivocal ethical dimension, being based on the recognition of the equal value of all lives and structured with the purpose of saving lives. The ethical scrutiny therefore focuses on the triage criteria: "first-come, first-served" and "high severity, high-priority", "rationing" and "rationalization" of resources. The SARS-CoV-2 pandemic unleashed unparalleled pressure on human and technical health resources, which led to a rationing triage, based on chronological age as a factor of exclusion, which violates human dignity and social justice. At the same time, it presents itself as an equivocal reality, with a weak argument, shaped by a language policy, and revealing a logic of action abusive of human rights, being, therefore, ethically unacceptable.

\section{Keywords}

Triage. Age. Rationing. Rationalization. Ethics.

\section{Resumen}

La triaje, o la priorización de pacientes, comenzó como una estrategia exitosa para salvar a la mayor cantidad posible de personas heridas. A lo largo de su corta trayectoria, el sistema de triaje ha ido evolucionando, respondiendo positivamente a las necesidades clínicas de

\footnotetext{
${ }_{1}^{1}$ Professora Catedrática de Ética, Departamento de História, Filosofia e Artes, Faculdade de Ciências Socias e Humanas, Universidade dos Açores, Ponta Delgada, Açores, Portugal. https://orcid.org/0000-0001-7246-6182. Email: m.patrao.neves@gmail.com
} 
los pacientes en distintas situaciones. Siempre ha asumido una dimensión ética inequívoca cuando se basa en el reconocimiento de la igualdad de valor de todas las vidas y cuando se estructura con el propósito de salvar vidas. Por tanto, el escrutinio ético se centra en los criterios de selección: "primero en llegar, primero en cuidar" y "máxima severidad, máxima prioridad", "racionamiento" y "racionalización" de recursos. La pandemia del SARS-CoV-2 desató una presión sin precedentes sobre los recursos humanos y técnicos de salud, lo que llevó a un cribado de racionamiento, basado en la edad cronológica como factor de exclusión, lo cual atenta contra la dignidad humana y la justicia social. Al mismo tiempo, se presenta como una realidad equívoca, con un argumento débil, moldeado por una política lingüística, y que revela una lógica de la acción abusiva de los derechos humanos, siendo, por tanto, éticamente inaceptable.

\section{Palabras clave}

Triaje. Edad. Racionamiento. Racionalización. Ética.

\section{Introdução}

Toda a triagem exige critérios e qualquer critério exige uma fundamentação ou justificação racional. No domínio da saúde os critérios são necessária e inicialmente de natureza clínica, isto é, de acordo a realização do bem do paciente, o que deveria permitir perspectivar a triagem como um processo relativamente objectivo e consensual, isto é, pacífico, não descurando a singularidade inerente a cada caso clínico. No entanto, em saúde pública, o doente não é apenas a pessoa, na sua dimensão individual, mas também a comunidade, na sua dimensão colectiva; e os valores da prática clínica, que já na esfera individual não são hegemónicos (e.g. o valor da recuperação da saúde pode entrar em conflito com o da autonomia do doente), no domínio comunitário têm sempre de ser articulados com outros valores de diferente natureza (e.g. valores culturais ou económicos) - o que introduz factores que complexificam a triagem. E quando eclode uma crise de saúde pública, como é uma pandemia, os meios assistenciais disponíveis são inexoravelmente insuficientes para responder positivamente a todas as necessidades, pelo que os critérios de triagem se tornam ainda mais difíceis de elaborar e aplicar, no respeito pelos princípios éticos estruturantes do nosso presente: a dignidade humana, no plano pessoal, e a justiça social, no plano comunitário.

\section{"Triagem": definição conceptual e apontamento histórico}

A palavra "triagem" é uma tradução do francês (galicismo) triage (substantivo que deriva do verbo trier, significando comummente "escolher") que se refere à acção de escolher, de "separar" entre muitos, de "selecionar". Este termo tem sido utilizado em diversos domínios, nomeadamente na agricultura ou na mineração, designando a selecção, 
respectivamente, de sementes ou minérios. No entanto, o conceito reporta-se hoje, mais frequente e directamente, ao âmbito da assistência clínica em que ganhou o sentido técnico específico de priorização de doentes, isto é, de selecção daqueles que devem ser assistidos em primeiro lugar, entre muitos outros que ficarão a aguardar, de acordo com critérios a estabelecer previamente.

Esta mais imediata acepção de "triagem" decorre do contexto histórico em que a noção se terá vulgarizado, no exercício de uma medicina de catástrofe, em situação de guerra, em que o demasiado elevado número de militares a necessitarem de cuidados médicos em relação aos recursos humanos e materiais disponíveis, obrigava a uma selecção de feridos a atender prioritariamente, em alternativa à assistência por ordem de chegada. Terá sido o cirurgião Dominique Jean Larrey, do exército napoleónico, no século XVIII, a gizar e implementar um método classificação de risco clínico e de selecção de feridos em batalha, tomando como único critério de priorização a gravidade clínica - categorizada em três níveis, os perigosamente feridos, os menos gravemente feridos e os ligeiramente feridos -, no sentido de conseguir proporcionar os melhores e mais rápidos cuidados aos que mais deles precisavam e tendo como único objectivo salvar o maior número possível de vidas (1) (2). A triagem supõe a organização efectiva da assistência clínica aos feridos no campo de batalho (que hoje se designa por hospital de campanha) e implica a opção deliberada por um critério de priorização de feridos, o que não é comum na história da medicina.

Neste processo, Larrey não considerava nem o posto militar, nem mesmo a nacionalidade, cuidando igualmente dos feridos inimigos, num testemunho eloquente de respeito pela vida de todas as pessoas e de sentido de justiça.

A triagem de desastre, que terá sido desenvolvida entre 1792-1801, foi pela primeira vez sistematicamente utilizada durante a I Guerra Mundial, tendo-se então generalizado pelo forte impacto que obteve na diminuição da mortalidade entre os militares (3). Aliás, foi este mesmo resultado muito significativamente positivo que motivou também a sua adaptação ao domínio civil.

O recurso ao sistema de triagem em contexto hospitalar e na prática clínica quotidiana, a partir da adaptação do seu originário domínio militar, verifica-se apenas na segunda metade do século XX, tendo Weinerman et al. relatado, em 1964, a sua implementação civil por vários serviços de urgência (4). Neste âmbito, vários modelos foram sendo desenhados e implementados, alguns genéricos para situações de emergência, outros dirigidos para cenários específicos, mas todos obedecendo à estrutura característica 
da triagem de classificação de risco e respectiva de priorização de pacientes. Por exemplo, a triagem de Manchester (MT), desenvolvida em 1994 por Kevin Mackway-Jones, no Manchester Royal Infirmary, no Reino Unido, é um sistema bastante abrangente e muito difundido nos países ocidentais e não só (e.g. adoptado também no Brasil) que se baseia no estabelecimento de cinco categorias clínicas de priorização de doentes a que, por conveniência de serviço, se faz corresponder cores diferentes: emergência, encarnado; muito urgente, laranja; urgente, amarelo; pouco urgente, verde; não urgente, azul. É na consideração do fluxograma, na hierarquização dos índices de avaliação e respectivo factor de ponderação, cuja contabilidade decidirá o encaminhamento a dar ao doente, que as discrepâncias se registam entre os vários modelos, não existindo um consenso universal a este nível (5). A problematização da triagem complexifica-se quando à avaliação clínica dos doentes e sua respectiva priorização, de acordo com o sistema adoptado, se soma a consideração dos recursos de saúde disponíveis e da sua necessária rentabilização, como se verifica no contexto da COVID-19 (6). A triagem torna-se não só particularmente complexa, mas passa também a explicitamente incluir factores de ponderação humana, pelo exige uma cuidadosa apreciação ética.

\section{Critérios gerais de Triagem: abordagem ética}

A recuperação da origem histórica da triagem permitiu-nos reconhecer o mérito ético da neutralização de todas as determinantes sociais como processo para alcançar um critério de selecção maximamente objectivo, o da gravidade clínica, e na observância de valores que consideramos estruturantes da nossa contemporaneidade. Verificámos, porém, que mesmo na consideração exclusiva do plano clínico, não existe um sistema de triagem consensual, universal. Além disso, o contexto de escassez de recursos reintroduz o factor humano na priorização dos doentes, o que confirma a ponderação ética da triagem como verdadeiramente incontornável. A triagem não está, pois, jamais, isenta de escrutínio ético.

Podemos, aliás, sublinhar que, desde a sua origem, se revestiu de uma dimensão ética preponderante uma vez que sempre teve como objectivo a preservação da vida e a recuperação da saúde do maior número de pessoas, protagonizando assim o princípio da justiça social, sob uma perspectiva teleológica utilitarista: o fim (telos) é a maximização do bem (ou utilidade). Simultaneamente, a neutralização das características sociais no processo de selecção dos feridos, confirma fundar-se no reconhecimento do valor incondicional da vida humana, assim protagonizando o princípio da dignidade humana, sob 
uma perspectiva deontológica: o dever (déon) estruturante é o valor absoluto, e por isso, idêntico, de todas as vidas humanas.

Deste modo, a questão ética mais complexa que a triagem coloca situa-se ao nível procedimental, isto é, da formulação e implementação de critérios, compreendendo-se hoje, melhor do que no passado, que a consideração do risco clínico é condição de objectividade na priorização dos doentes, mas não elimina a subjectividade do processo por via da consideração de outros factores associados à triagem. E estes ganham mais peso na justa proporção em que os recursos assistenciais se tornam mais escassos o que, sendo uma possibilidade na medicina de emergência, é uma realidade na medicina de catástrofe.

Triagem em Medicina de Emergência: "primeiro a chegar, primeiro a cuidar" e "máxima severidade, máxima prioridade"

A triagem no quotidiano da medicina de emergência é dita estruturar-se essencialmente por dois diferentes comuns princípios de acção. O inicial a ser implementado é o de "primeiro a chegar, primeiro a cuidar" (first-come, first-served), isto é, os pacientes são atendidos por ordem de chegada. De facto, porém, se os pacientes forem atendidos à medida que chegam, não se procede a qualquer priorização pelo que, na verdade, se estará a um nível que classificaríamos de "pré-triagem". Se, entretanto, este critério de "primeiro a chegar, primeiro a cuidar" se mantivesse perante um fluxo acrescido de pacientes, enquanto se formava uma lista de espera, estaríamos, genericamente, perante o modelo da lotaria. Neste, é o acaso, ou seja, circunstâncias externas à realidade clínica e não humanamente controláveis, como a ordem de chegada, que decidiriam a priorização do atendimento, o que classificaríamos então como "a-triagem", ou seja, ausência efectiva de triagem.

Teoricamente, o critério da lotaria tem sido defendido por alguns autores como sendo o mais justo quando não é possível formular uma qualquer normativa consensual de justiça. Por outro lado, também tem sido interpretado como um acto de desresponsabilização por parte de quem compete a decisão, numa abdicação ou demissão do dever de o fazer, deixando a decisão ao curso de acontecimentos, sem qualquer interferência humana.

O sistema "primeiro a chegar, primeiro a cuidar", porém, apenas potencializa o número de vidas salvas e rentabiliza os recursos existentes enquanto os pacientes puderem ser atendidos à medida que chegam. A partir do momento em que o número de pacientes a carecer de assistência clínica aumenta gerando tempo de espera, este sistema perde a sua validade clínica e, por isso também, a legitimidade ética que, não obstante ser mais exigente 
do que a clínica, a supõe como base (o que é clinicamente reprovável, jamais poderá ser eticamente aceitável).

Toma lugar então um segundo critério, o da "máxima severidade, máxima prioridade" (high severity, high-priority) que corresponde, afinal, ao que o sistema de triagem inaugurou na priorização da assistência determinada única e exclusivamente por critérios clínicos, sendo o que hoje domina os serviços de urgência médica. Os doentes que apresentam uma situação clínica mais grave (avaliada a partir dos fluxogramas nem sempre coincidentes em todos os modelos) são os que ganham prioridade em qualquer sistema de triagem. A priorização do atendimento dos doentes mais graves traduz-se num aumento das possibilidades quer de sobrevivência, quer de uma recuperação plena sem sequelas.

Entretanto, a regra do "primeiro a chegar, primeiro a cuidar" apenas se mantém válida entre pessoas com uma análoga situação clínica não-urgente.

\section{Triagem em Medicina de Catástrofe: "racionamento" e "racionalização"}

Assim como a regra do "primeiro a chegar, primeiro a cuidar" perde legitimidade ética quando o volume de doentes num determinado período tempo gera espera no atendimento, também a regra da "máxima severidade, máxima prioridade" perde legitimidade quando ocorre uma situação de aumento excepcional do volume de doentes, num curto espaço de tempo (7). Tal verifica-se, regra geral, no contexto de guerra, de desastre natural e de pandemia, ou seja, numa medicina de catástrofe (8). Em realidades extremas, como estas, em que os recursos disponíveis não são suficientes para assistir todos os que carecem de cuidados médicos, a priorização pode excluir não apenas os doentes menos graves, mas também os mais graves, aqueles avaliados como de recuperação muito improvável ou ainda os de recuperação pouco provável que exigiriam um significativo investimento de recursos também necessários para outros doentes com mais possibilidades de recuperação. Este tipo de ponderação, ausente aquando dos primeiros ensaios de triagem em cenário de regra, conduz a novos critérios de priorização de doentes, comummente designados por "racionamento" e "racionalização".

"Racionamento" e "racionalização" são termos com uma mesma raiz etimológica (ratio, onis) o que determina a sua proximidade conceptual: ambos se referem ao exercício da razão, respectivamente, ao cálculo ou produto da razão e à capacidade de calcular. Além disso, são quase homófonos, pelo que não raramente são confundidos (o que verifica mesmo na bibliografia bioética, sobretudo centrada no "racionamento", recorrendo mais 
raramente à noção de "racionalização" e então tomando-a frequentemente como sinónimo de "racionamento"). Não obstante, a sua operacionalização, ou intervenção no processo de priorização de doentes em situação de insuficiência de recursos para todos, estabelece uma distinção essencial com um impacto decisivo na sua avaliação ética. De facto, estes dois conceitos referem-se a procedimentos bem distintos que se fundamentam também diferentemente e se revestem de uma distinta legitimidade ética (9).

O "racionamento" tem uma conotação tendencialmente negativa, referindo-se à distribuição de uma quantidade reduzida de bens que, como tal, só pode contemplar um número reduzido também de pessoas. Foca-se, assim, no processo de carácter administrativo de regulação e principalmente de controle da distribuição de bens limitados. São então estabelecidos critérios de distribuição dos bens disponíveis. Por exemplo, quem tem acesso às vacinas existentes? Os profissionais de saúde que não só são as pessoas mais expostas, mas também as mais necessárias para tratar os doentes? Os grupos mais vulneráveis à Covid-19 e em que se verificam as mais elevadas taxas de letalidade, como os idosos, sobretudo os que vivem em lares?

A "racionalização", por sua vez, tem uma conotação tendencialmente positiva, referindo-se à optimização ou rentabilização dos recursos existentes, isto é, ao aproveito máximo de todos os recursos na produção do máximo bem possível. Foca-se, assim, no processo de reorganizar os sistemas ou processos anteriormente adoptados (e. g. reorganização dos espaços, equipamentos e actuação dos profissionais de saúde no sentido de, com os mesmos meios, conseguir satisfazer as necessidades de mais doentes), tonando as decisões mais lógicas e justificáveis, bem como mais consistentes e eficientes. Quem vai ter acesso a cuidados intensivos, à ventilação invasiva quando, devido ao número insuficiente de ventiladores, nem todos podem beneficiar deles?

Numa situação de "racionamento" o hospital sabe não ter capacidade para atender todos os doentes e estabelece critérios para selecionar aqueles de que pode cuidar. Esses critérios podem ser muito variados: os doentes mais novos, os nacionais, os profissionais de saúde, as figuras do Estados, etc. Do ponto de vista ético o mínimo exigível é que os critérios sejam transparentes, racionalmente justificáveis e consensualmente reconhecidos como justos. Em todo o caso, violarão sempre o princípio da dignidade humana porque a selecção será feita a partir de características pessoais, atribuindo-se um diferente valor a diferentes pessoas as quais, na fidelidade ao princípio da dignidade humana, têm todas o mesmo valor, isto é, um valor absoluto e incondicional. A 'dignidade humana' refere-se ao valor absoluto 
(total, sem graus), incondicional (independente de qualquer condição), inalienável (não eliminável) e intrínseco (constituinte identitário) de todo o ser humano, o que não é compatível com qualquer forma avaliação a partir de características naturais.

Numa situação de "racionalização" o hospital também sabe não ter capacidade para atender todos os doentes e ter de estabelecer critérios para selecionar aqueles de que pode cuidar. Porém, desloca os critérios de ponderação da pessoa em causa para a origem do problema: a escassez dos recursos. Importa então optimizá-los, isto é, produzir o máximo bem com os poucos recursos existentes. A escolha passa a ser feita em função das probabilidades de sobrevida, beneficiando dos cuidados quem tem hipóteses efectivas de sobreviver e encaminhando-se os doentes com pior prognóstico para cuidados de conforto (paliativos). Deste modo, a distribuição dos limitados recursos disponíveis processa-se a partir do impacto do seu desempenho em cada um dos seus possíveis beneficiários, num exercício maximizado da sua função: os recursos terapêuticos existentes são alocados às situações clínicas que deles mais possam beneficiar, em que o seu desempenho possa ser optimizado, independentemente, por exemplo, da profissão (escolhida pelo) do doente ou da sua idade (que natural e inevitavelmente vai somando). Respeita-se assim a dignidade humana e preserva-se também a justiça social na medida em que, apesar de nem todos os doentes virem a receber assistência terapêutica, não se procede a qualquer discriminação entre eles.

Brevemente, diríamos que, enquanto o racionamento se foca nos doentes e suas características pessoais, a racionalização se foca nos recursos e no seu desempenho. Ambas as abordagens podem ser apoiadas por uma concepção utilitarista da justiça pois, por vias diferentes, ambos visam a maximização do bem; porém, o racionamento permite o sacrifício de algumas pessoas em prol do bem da maioria, o que a fidelidade ao princípio da dignidade humana, por via da racionalização, impede.

Em síntese, numa situação quotidiana de emergência médica, prioriza-se os doentes com pior prognóstico; numa situação excepcional de escassez de recursos, excluem-se os que têm pior prognóstico, o que apenas será eticamente justificável se obedecer a um critério de racionalização dos recursos disponíveis e não do seu racionamento.

\section{A "idade" como factor na triagem por racionamento: perspectivação ética}

Durante a pandemia de SARS-CoV-2, e particularmente em períodos de pico em que a enorme afluência de pacientes muito graves ia esgotando os recursos técnicos e humanos 
existentes, a priorização de doentes COVID-19 adoptou, frequente e tacitamente, a característica da "idade" como filtro para a admissão em cuidados intensivos, para o acesso a ventilação invasiva, um recurso terapêutico absolutamente vital nos casos mais graves: doentes com mais de 80 anos, ou de 75, ou 70, uma idade a especificar conforme a quantidade dos meios de assistência clínica disponíveis a cada momento, foram apenas encaminhados para cuidados de conforto, sem investimento na sua recuperação. A "idade" constituiu-se assim como um factor de exclusão - não se admitindo doentes a partir de uma determinada idade -, ou de secundarização no acesso (10) - admitindo-se o idoso nos cuidados intensivos apenas na ausência de pressão sobre os recursos.

Tal correspondeu a um critério de "racionamento" na triagem de pacientes, na já apontada violação grosseira do princípio da dignidade humana, numa talvez inconsciente percepção deturpada da dignidade humana como uma realidade tangível, material, susceptível de se ir gastando com o uso. E, no entanto, apesar desta perspectiva parecer determinante em situações de escassez extrema de recursos, ela não é eticamente argumentável (11), tropeçando em vários diferentes tipos de obstáculos na sua justificação, os quais aqui sistematizamos.

\section{Uma realidade equívoca}

O primeiro obstáculo desta atitude discriminatória dos mais velhos é um óbvio equívoco em que assenta a consideração da "idade" como factor de exclusão, na negligência da diferença entre a idade cronológica e a idade biológica: a primeira é de carácter administrativo e indica o tempo físico decorrido desde o dia do nascimento até ao presente; a segunda, de natureza biológica e corresponde ao índice de envelhecimento de cada pessoa traduzindo a sua real idade. As duas nem sempre coincidem. Na clínica geral quotidiana, é a idade biológica que se torna um factor preponderante da prestação de cuidados de saúde adaptados, personalizados; todavia, na triagem em tempo de pandemia apenas a idade cronológica foi considerada.

Neste equívoco contexto, torna-se se possível priorizar um doente cronologicamente mais jovem em detrimento de um outro biologicamente mais jovem, assim contrariando o objectivo geral de estruturação de um sistema de triagem de investir mais em quem teria mais possibilidades de sobrevivência. Aliás, este objectivo superior poderá mesmo ser duplamente deturpado quando se utiliza a "idade" como factor de exclusão uma vez que este 
procedimento também conduz a subestimar critérios médicos objectivos, nomeadamente a existência de comorbilidades.

\section{Uma argumentação débil}

O segundo obstáculo da assunção da idade cronológica como factor de exclusão reporta-se a uma tripla argumentação utilitarista convergente na discriminação dos mais velhos: os idosos já viveram mais tempo que os outros; a sua 'expectativa de vida' é mais reduzida; tal como a sua 'qualidade de vida' é menor (12).

É evidente e incontestável que as pessoas mais velhas já viveram mais tempo do que as mais novas. Porém, este facto não retira nem acrescenta qualquer valor à vida de cada um, a qual é em si mesma um absoluto. Não é, pois, comparável a "comeu mais do que outros, pelo que já não precisa de comer tanto como estes" ou "gastou mais tempo a intervir do que os outros, pelo que já não pode dispor do mesmo tempo do que estes". Sendo um absoluto, uma totalidade indivisível, a vida também não é susceptível de quantificação ou qualificação. Deste modo, poder-se-á afirmar que a 'expectativa de vida' dos mais velhos é mais reduzida do que a dos mais novos, mas trata-se apenas de um valor estatístico que não constitui uma realidade efectiva para as pessoas em causa: todos os dias há jovens que falecem e idosos que ultrapassam a expectativa média de vida. Nenhuma pessoa singular pode ser tratada em função de uma média aritmética relativa a outras pessoas em situações análogas ou diferentes, o que corresponderia ao desrespeito da sua identidade pessoal, singular, e à rejeição de uma medicina centrada na pessoa. Este mesmo argumento é válido para rejeitar a afirmação categórica de que o idoso tem uma 'qualidade de vida' menor. Porém, em relação a este aspecto o fundamental é a impossibilidade de outrem, que não o próprio, qualificar a sua vida, o que constitui sempre, inexoravelmente, um exercício subjectivo. Os parâmetros que ao longo de largos anos têm sido ensaiados para uma avaliação objectiva da "qualidade de vida" são certamente relevantes na opção por terapêuticas alternativas, com o envolvimento do próprio, mas perdem validade quando se tornam o parâmetro decisivo para deixar morrer ou tentar salvar.

\section{Uma política de linguagem}

O terceiro obstáculo na justificação da exclusão dos mais velhos é o da tendência para a opacidade da argumentação, quando não mesmo o recurso a uma política de linguagem, bastante útil para falsear a realidade em causa, inquinar o debate e iludir a 
opinião pública. Com efeito, as expressões anteriormente citadas - de 'expectativa de vida' e de 'qualidade de vida' - apresentam-se como axiologicamente neutras, tendendo a substituir a referência à 'idade' numa pouco transparente política de linguagem. Este aspecto torna-se ainda mais evidente quando se substitui a expressão unanimemente positiva de "salvar vidas" por uma outra, pretensamente sinónima de "salvar anos de vida". Esta orientação utilitarista preconiza o cálculo da eficácia, por exemplo, de um ventilador (numa perspectiva já não de racionamento, mas de racionalização) não pela probabilidade de recuperação da COVID-19, mas pelos anos de vida saudável que poderá vir a ter o que, inexoravelmente, penaliza os mais velhos. Aliás, este enganoso critério de "salvar anos de vida" (numa cada vez mais comum maximização da expectativa de vida) só é activado quando há pacientes seniores envolvidos (o que o evidencia como critério deliberado de exclusão) e nunca em situações envolvendo outras faixas etárias (e.g. se um bebé e um jovem adulto estiverem em risco de vida numa situação de escassos recursos clínicos, os cuidados disponíveis serão canalizados para o que tiver mais probabilidades de sobreviver, sem atender à esperança média de vida que se lhes aplica respectivamente).

Tal corresponde a uma estratégica semântica para, de maneira sub-reptícia, empregar o critério "idade" sem o assumir e sem tão pouco ter a obrigação, impossível de cumprir, de o justificar eticamente. Com efeito, para "salvar anos de vida" convirá preferir os pacientes mais jovens aos mais velhos, dada a já referida e também argumentada menor expectativa de vida.

\section{Uma lógica de acção abusiva dos Direitos Humanos}

O quarto obstáculo à exclusão de pessoas com base na idade cronológica é de longo alcance na medida em que a sua generalização ultrapassaria largamente os impactos directos nas pessoas concretas implicadas e conduziria a um retrocesso moral profundo. Com efeito, a discriminação de pessoas fundamentada em caraterísticas naturais, em relação às quais a própria pessoa não tem qualquer responsabilidade ou poder, foi já proscrita das sociedades que adoptaram a doutrina dos Direitos Humanos como moral comum. Tornou-se eticamente reprovável, politicamente criticável e legalmente sancionável toda e qualquer discriminação, por exemplo, em função do género ou da etnia, mas também da religião ou da ideologia, estando a idade ao nível das primeiras, de carácter físico (natural). 
A lógica de exclusão por características físicas exclusivamente admitida para o factor idade, seria incoerente e sem qualquer justificação racional. Simultaneamente, expor-se-ia aos riscos inerentes à "vertente deslizante", isto é, à facilitação de uma crescente abrangência de uma inicial excepção que assim o deixaria de ser. Depois da discriminação em função da idade, poder-se-ia, coerentemente, alargar a exclusão a muitas outras pessoas, nomeadamente: portadoras de deficiência (13), com doenças genéticas ou crónicas.

\section{Em jeito de balanço}

O factor "idade" biológica terá de ser ponderado na priorização de acesso a recursos terapêuticos vitais sempre conjuntamente com os demais indicadores relevantes para a avaliação clínica da pessoa (14) e nunca só por si $(15,16)$, a partir do que se procederá à racionalização dos meios disponíveis. A racionalização exige que se priorizem as pessoas que têm possibilidade de beneficiarem efectivamente dos meios disponíveis. A inclusão ou a exclusão não decorre de características da pessoa, mas da possibilidade de sobrevida. A triagem por racionalização promove a justiça como equidade, na maximização dos benefícios sociais e no tratamento igualitário de todos os cidadãos, assim também respeitando a dignidade humana, não excluindo ninguém. Este é um sistema eticamente válido para qualquer situação clínica que exija triagem.

\section{Referências}

1. Skandalakis PN, Lainas $P$, Zoras $O$, Skandalakis JE, Mirilas P. To afford the wounded speedy assistance: Dominique Jean Larrey and Napoleon. World J Surg. 2006 Aug;30(8):1392-9. doi: 10.1007/s00268-005-0436-8. PMID: 16850154.

2. Nakao I, Ukai, I, Kotani J. A review of the history of the origin of triage from a disaster medicine perspective. Acute Med Surg. 2017 Oct;4(4):379-384.

3. Slawson R. The Development of Triage. National Museum of Civil War Medicine. National Museum of Civil War Medicine [Internet]. June 19th 2017. Disponível em: https://www.civilwarmed.org/surgeons-call/triage/

4. Yancey CC, O'Rourke MC. Emergency Department Triage. 2020 Jun 5. In: StatPearls [Internet]. Treasure Island (FL): StatPearls Publishing; 2020 Jan-. PMID: 32491515.

5. Bazyar J, Farrokhi M, Khankeh H. Triage systems in Mass Casualty Incidents and Disasters: A Review Study with a Worldwide Approach. J Med Sci. 2019 Feb 15;7(3):482494. 


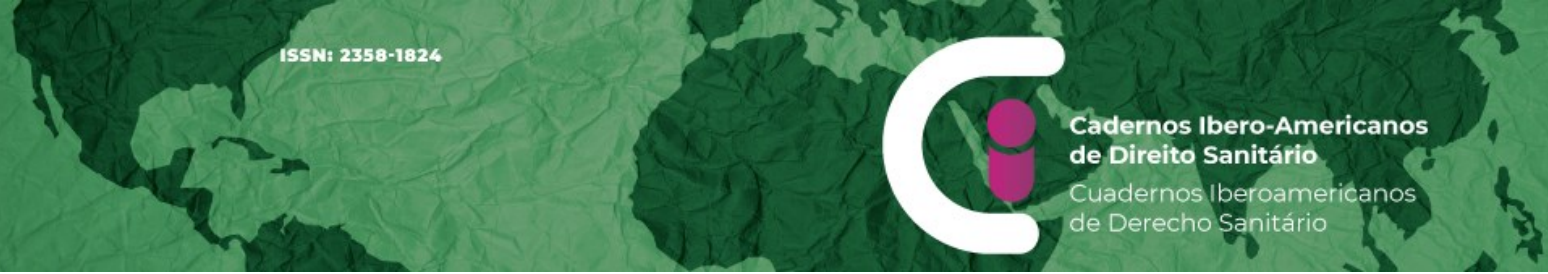

6. Hawryluck L. Ethics of Triage. ICU Management \& Practice, ICU Volume 10 - 4 - Winter, 2010/2011. Disponível em: https://healthmanagement.org/c/icu/issuearticle/ethics-of-triage

7. Patrão Neves MC. Ethical implications of 'Rationing' vs 'Rationalization'. Eubios Journal of Asian and International Bioethics. May 2020;30(4):134.

8. Rigal S, Pons F. Triage of mass casualties in war conditions: realities and lessons learned, International Orthopaedics (SICOT). 2013;37:1433-1438. doi:

https://orcid.org/10.1007/s00264-013-1961-y

9. Patrão Neves MC. Ethical health resources allocation: Why the distinction between 'rationing' and 'rationalization' matters. Revista de Bioética y Derecho. 20 nov. 2020;63-79. Disponível em: https://revistes.ub.edu/index.php/RBD/article/view/32044/32165

10. Beauchamp T, Childress J. Principles of Biomedical Ethics. $6^{a}$ ed. New York/Oxford: Oxford University Press; 2009. pp. 272-273.

11. Carrieri D, Peccatori F, Boniolo G. COVID-19: a plea to protect the older population. Int J Equity Health. 2020;19:72.

12. Emanuel EJ, Persad G, Upshur R, Thome B, Parker M, Glickman A, Zhang C, Boyle C, Smith M, Phillips JP. Fair Allocation of Scarce Medical Resources in the Time of Covid-19. N Engl J Med. 2020 May 21;382(21):2049-2055. doi: https://orcid.org/10.1056/NEJMsb2005114. Epub 2020 Mar 23. PMID: 32202722.

13. Solomon M Z, Wynia MK, Gostin LO. Covid-19 Crisis Triage - Optimizing Health Outcomes and Disability Rights. The New England Journal of Medicine. 2020 [consulta em 12.06.2020]. Disponível em: https://www.nejm.org/doi/full/10.1056/NEJMp2008300

14. Caplan A. New York's bioethics experts prepare for wave of difficult decisions. Washington Post. March 282020 [consulta em 12.06.2020]. Disponível em: https://www.washingtonpost.com/world/national-security/new-yorks-bioethics-expertsprepare-for-a-wave-of-difficult-decisions/2020/03/28/4501f522-7045-11ea-a3ec70d7479d83f0 story.html

15. Deutscher E. Solidarity and Responsibility during the Coronavirus Crisis, Ad Hoc Recommendation. 2020 [consulta em 12.06.2020]; 3-4. Disponível em: https://www.ethikrat.org/fileadmin/Publikationen/Ad-hocEmpfehlungen/englisch/recommendation-coronavirus-crisis.pdf

Patrão Neves MC. Critérios de triagem em pandemia: o factor idade. Cadernos Ibero-Americanos de Direito Sanitário. 2021 abr./jun.;10(2):110-122.

https://doi.org/10.17566/ciads.v10i2.776 